\title{
Assessing the Impact of Management Concerns in E-business Requirements Planning in Manufacturing Organizations
}

\author{
John Dilworth and Ashok Kochhar \\ School of Engineering and Applied Science \\ Aston University, Birmingham, United Kingdom \\ a.k.kochharaaston.ac.uk
}

\begin{abstract}
This paper describes the application of a model, initially developed for determining the e-business requirements of a manufacturing organization, to assess the impact of management concerns on the functions generated. The model has been tested on 13 case studies in small, medium and large organizations. This research shows that the incorporation of concerns for generating the requirements for e-business functions improves the results, because they expose issues that are of relevance to the decision making process relating to e-business. Running the model with both and without concerns, and then presenting the reasons for major variances, can expose the issues and enable them to be studied in detail at the individual function/ reason level.
\end{abstract}

Keywords: E-Business, Requirements Planning, Manufacturing, Management Concerns, Company characteristics, Supply Chain, Collaborative Working.

\section{Introduction}

E-business as a concept emerged around the turn of the millennium. During the intervening period, e-business (in so far as it is applied to business-to-business interaction between manufacturing and distribution organizations) seems to have become almost indistinguishable from modern thinking in Supply Chain Management.

The theory of optimization, collaboration and timely information availability seem central to supply chain management thinking [for example1, 2 and 3]. The essential point is that strategic supply chain management demands collaboration among all participants in the value chain. The real business benefits only occur when the entire supply chain is optimized. The problem is that the whole concept stands or falls by collaboration so that everyone will behave for the greater good. If it can be achieved, it may be worth doing; if it cannot for whatever reason (politics, human behavior, relative power structures, sufficient information availability) then the whole thing can be a potentially expensive failure to achieve anything worthwhile.

The e-business domain therefore deals with functionalities that not only are under the control of external organizations (for example customers and suppliers) but 
functionalities that are only of any meaning when such organizations are working collaboratively. Any attempt to assess the relevance of e-business concepts must therefore find a way of dealing with the subjective concerns that might exist as to factors that may inhibit such collaborative working. For example buyers and sellers could use some sort of collaboration tool to upload forecasts and actual plans, and then both a given buyer and seller could go into a collaborative mode to come to a common understanding and consensus on what the seller is going to supply to the buyer. The question begged is whether this behavior is realistic taking into account politics, human behavior and the realities of business. It would seem therefore that any attempt to assist organizations with assessing the relevance of possible e-business initiatives must find a way of reflecting the impact of these "softer" issues in determining the initiatives that are likely to be practical and hence beneficial. This paper describes the development of and experience with an e-business requirements model that attempts to deal with these more subjective concerns that might exist as factors inhibiting such collaborative working.

\section{An E-business Requirements Model to Deal with Concerns}

There are many reported examples of "models" [4, 5, 6, 7 and 8] that find ways in which e-business activity can be categorized so that its structure can be understood. While all of these can provide useful insights into the e-business concept, an approach that dealt with specific detailed functions was felt to be required. Dilworth and Kochhar [9] proposed a systematic process that can propose at a useful level of detail the probable e-business requirements of an organization based on objective criteria. They went on to describe the creation, testing and validation of an e-business requirements specification model to provide such a systematic process. The model constructed contained all the functions relating to the process of buying, selling, or exchanging products, services, and information via computer networks.

The functions supported by the model are organised into three broad categories

- Demand Side Functions;

- Supply Side functions relating primarily to "outside" partners;

- Supply Side Functions relating primarily to "inside" the organization.

The Demand Side Functional Domains were

- Product Development and pre-production - the functions involved in communicating customer-related design and engineering information and change requests.

- Demand Management - the communications relevant to the process of creating and recording customer demand within the organization's systems.

- Supply Chain Planning - the functions involved in the process of responding to the customer's supply chain planning requirements of you as a supplier

- Outbound Logistics - the communications relevant to the dispatch of goods, to and from the customer and other external partners. 
- Customer Accounting - the communications with customers or other financial organizations relating to the receiving of money for goods sold.

- Service - For those organizations that provide post sales service the functions relating to the management of remote service activity

The Supply Side "outside” functional domains were

- Product Development and pre-production - the functions involved communicating supplier-related design and engineering information and change requests.

- Supply Chain Planning - the functions involved in the process of planning what needs to be supplied by external suppliers and other partners.

- Purchasing and Procurement - the interactions relevant to the management of the supplier base and the communication of demand to the supplier.

- Inbound logistics - the communications to and from the supplier and other external partners that are relevant to the receiving of goods.

- Manufacturing - in a manufacturing "network" situation, the communications necessary between partner plants and sub contractors.

- Supplier Accounting - the communications with suppliers or other financial organizations relating to the payment of money for goods supplied

- Maintenance - the functions related to communication with external partners involved in planning and executing maintenance activity

The Supply Side "inside” functional domains were

- General Finance - includes those financial management, planning, budgeting or treasury activities conducted amongst separated groups within an organization

- Administration - administration systems managed on a centralized basis (e.g. personnel records, time recording) involving geographically dispersed groups.

\section{$3 \quad$ Model Structure}

A preliminary rationale (i.e. a set of reasons) was produced, based on expert knowledge and discussions with industrialists, in order to link these e-business functions to possible objective characteristics and subjective management concerns.

- Characteristics were defined as facts about the business. In principle, company characteristics are intended to be as objective and factual as possible and should be capable of being measured or counted or at least estimated to a reasonable level of accuracy. The number of customers, or the number of items dispatched per year are examples of such facts.

- Concerns are defined as the attitudes or opinions, concerning internal constraints and/or customer/supplier behavior, which can influence the relevance or practicality of e-business functions. Concerns could conceptually be thought of as being either a reason for doing something (for example the opinion of excessive current clerical activity could be a motivation for automating a clerical task), or a reason 
for lack of confidence in the success of an initiative (for example suppliers are not sufficiently technologically competent).

A reasoning structure was developed to link the characteristics and concerns of the company through detailed reasoning to an overall verdict as to the overall relevance of a given function. The model thus produced was tested on a variety of case studies and was demonstrated as improving in reliability as case studies progressed. Methods were developed whereby conclusions from the model could be presented at a "management" level of detail, and whereby useful insights could be provided.

In this model the concept of management concerns was added to objective factual characteristics. Concerns were intended to address the issue of how internal attitudes or customer/supplier behavior can make or break the relevance of certain functionalities irrespective of the objective relevance or otherwise of these said functions. In the model, concerns tended to have one of two effects:

- They represent a problem that ought to be a motive for interest in an e-business function (for example excessive current clerical activity ought to be a motivation for automating a clerical task);

- They represent a problem that would tend to prevent an e-business function from being useful, or a reason for lack of confidence in the success of an initiative (e.g. our suppliers cannot cope with our e-business oriented communication with them).

Discussion of the impact of concerns uses a synthesis of the detailed results of the model that was described as an "e-business profile". This is a simple analysis of the proportion of functions triggered (in relation to the total of those possible) in each functional domain converted to a percentage score and presented visually. This provides a simplified presentation, of what are in fact very detailed results, in an accessible format.

Testing of the computerized model in 13 manufacturing organizations has shown that it can generate E-business requirements with a high level of accuracy and requires typically one man day of effort compared to months required to carry out the same task using conventional systems analysis techniques. [9]

It was possible to use these profiles to discuss in general terms the potential impact of management concerns in the achievement of e-business possibilities. Running the model both with and without taking into account the management concerns makes it possible to gain additional insight. A version without concerns potentially provides a more objective analysis, while using the version with concerns brings in more subjective factors. By analyzing the difference between the two, the potential was recognized for achieving extra insights, for example:

- What are the real needs of the organization as opposed to what can be reasonably expected to give benefits assuming current attitudes?

- Which areas of e-business are most adversely affected by current attitudes and concerns?

- How difficult might be the implementation of e-business functions? 
The model run without concerns can therefore be regarded as an indication of the theoretical relevance of the functions to the organization, whereas the version with concerns represents the relevance of the functions in a practical world where theory cannot always be perfectly applied! The concept could also be used as an indication of the barriers likely to be encountered in an e-business implementation, and the consequent ease of implementation and probability of success.

\section{The Impact of the Concerns across 13 Case Studies}

The model has currently been used in thirteen case studies to develop the e-business requirements of manufacturing organizations. These case studies provided some interesting insights both into the potential relevance of e-business in a selection of manufacturing industry and also into the varying impact of these concerns. Figure 1, below, shows the e-business profile of a notional company representing a composite of all the case studies.

\section{Composite profile all Case Studies}

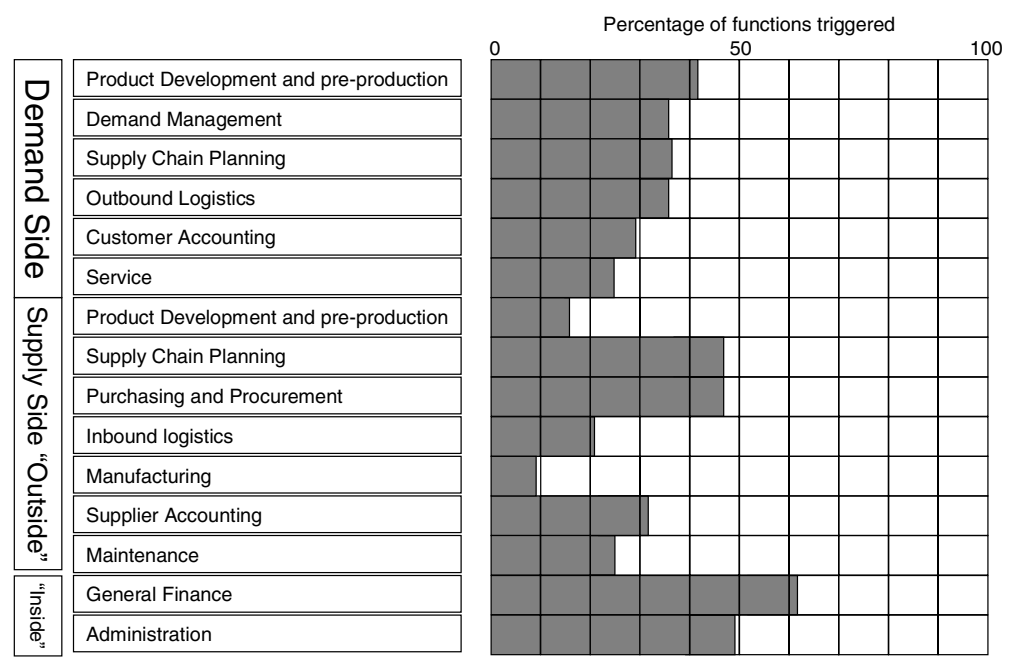

Fig. 1. Composite e-business profile

This is the full output from the model including the effect of management concerns. It shows the "average" (over all the case studies) relevance of e-business functions as predicted by the model. In the e-business profiles, the functions are organised into the three same three broad categories indicated earlier:

- Demand Side Functions;

- Supply Side functions relating primarily to "outside" partners;

- Supply Side Functions relating primarily to "inside" the organization. 
In effect this composite profile represents a "league table" of popularity of e-business functions at least in so far as it affects the thirteen case studies. This is interesting primarily as a weighted assessment of e-business function relevance against the sample of British Industry that our case studies represent. The most relevant are:

- The General finance and Administration side representing activities largely internal to the organizations involved;

- The supply chain and purchasing activities oriented to the procurement of goods

On the demand side, there is a more consistent level of coverage among the functional domains. The most popular (just) e-business functions relate to Product Development with customers. For the domains of Demand Management, Supply Chain Planning and Outbound Logistics, roughly one third of the possible functions were considered relevant for the case study sample. Service functions were less triggered, but this relates more to the fact that not all the case studies provided such functions to a significant degree. Of those that did, not all managed these using remote based resources or external organizations for which electronic communication would be relevant.

On the supply side far more variability of functional coverage was encountered. The most popular functions were Supply Chain Planning, Purchasing and Procurement, General Finance and Administration. At first glance it might appear to be anomalous that the functions associated with Product Development with Suppliers were not more popular. This actually is explained by the fact that many of such functions depend on the capabilities of suppliers, and in most case studies the suppliers represented smaller, less capable organizations than the case study organizations themselves (the customers).

Manufacturing functions were by contrast the least triggered. This is perhaps to be expected because most manufacturing activity is intra rather than inter organization, but it also reflects the decreasing importance of manufacturing to some of the case study organizations. Maintenance functions were also less triggered, but this relates more to the fact that not all managed these using external organizations, for which electronic communication would be relevant.

To illustrate the impact of concerns, a second profile is provided in figure 2 . The area shaded in black illustrates the additional degree of functionality that would have been considered relevant if the business concerns were ignored.

As can be seen overall, removing the concerns tended to increase the number of ebusiness functions that were considered relevant, but within that it is difficult to detect a pattern.

A more interesting pattern is provided by profiles that illustrate, for each case study, the e-business functions actually triggered as a percentage of all the possible ebusiness functions that could have been triggered. These can be visualized as an indication of an overview of the relevance of the e-business concept to each of the case studies. 


\section{Composite Concerns Profile all Case Studies}
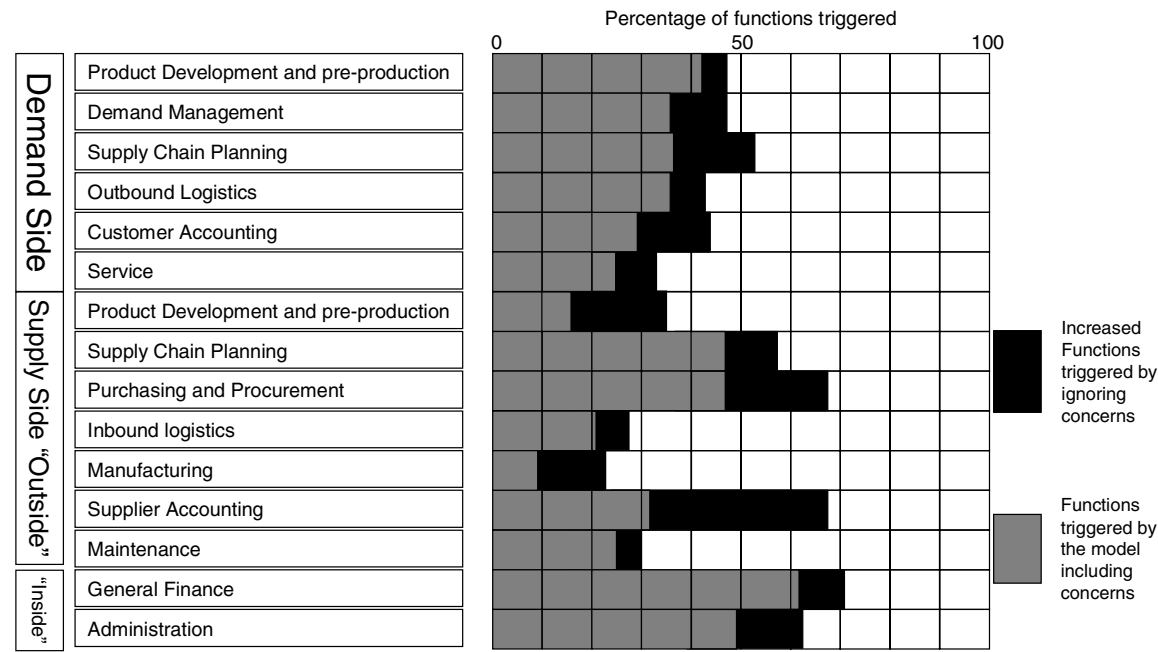

Fig. 2. Composite e-business profile with and without concerns

\section{Conclusions}

It can be concluded that the arguments in favor of concerns (the fact that the results are more realistic and useful) prevail against the counter-argument of undue pessimism. The key point is that the effect of these concerns in individual detailed cases can be studied at a detailed level, and therefore overridden if the effect of the concerns is unreasonable in an individual case. Having established that concerns are useful, the question arises as to whether there a value is producing results both taking concerns into account and ignoring them. Most concerns proved to be inhibitor concerns, the inclusion of which in the model tended to suppress the potential relevance of ebusiness functions. Excluding them would suggest that a function was relevant; including them would suggest that a concern was not relevant. For example suppose an e-business supply chain initiative is considered relevant in the absence of concerns, but concerns involving lack of support from management or lack of adequate capability of suppliers render it irrelevant. Which of these judgments is the most useful? The answer is either - depending on circumstance. The judgment including concerns could be a correct reflection of the likelihood of an organization making a success of a particular function. However the version without concerns could be an inspirational reflection of the potential for e-business in an organization providing that there was determination to address the said concerns.

Running the model both with and without concerns, and then presenting the reasons for major variances, can expose the issues and enable them to be studied in detail at the individual function/reason level. An e-business specification ignoring concerns 
is a useful indication of the objective relevance of the e-business functions to the organization in a reasonably concern-free world, whereas a version with concerns represents the relevance of the functions in a practical world where theory cannot always be perfectly applied! The original idea was that by exploring the difference between the two, an indication could be obtained of the significance of the difficulties of implementation of e-business functions that otherwise might have a theoretical application. Although not perfect or fully developed, it was concluded that the concept was useful in most cases in exposing some of the barriers that could inhibit an ebusiness implementation. It could therefore be regarded as a useful indicator of the consequent ease of implementation and probability of success.

\section{References}

1. Kehoe, D., Boughton, N.: New paradigms in planning and control across manufacturing supply chains, The utilization of Internet technologies. International Journal of Operations \& Production Management 21, 582-593 (2001)

2. Horvath, L.: Collaboration: the key to value creation in supply chain management. Supply Chain Management: An International Journal 6, 205-207 (2001)

3. Reyes, P., Raisinghani, M.S., Singh, M.: Global Supply Chain management in the Telecommunications industry: The role of information technology in Integration of Supply Chain Entities. Global Supply Chain Management 5(2), 48-67 (2002)

4. Bakker, E., Zheng, J., Knight, L., Harland, C.: Putting e-commerce adoption in a supply chain context. International Journal of Operations \& Production Management 28, 313-330 (2008)

5. Burn, J., Ash, C.: A dynamic model of e-business strategies for ERP enabled organizations. Industrial Management \& Data Systems 105, 1084-1095 (2005)

6. Cullen, A.J., Webster, M.: A model of B2B e-commerce based on connectivity and purpose. International Journal of Operations \& Production Management 27, 205-225 (2007)

7. Jackson, M.L., Sloane, A.: A model for analyzing the success of adopting new technologies focusing on electronic commerce. Business Process Management Journal 13, 121-138 (2007)

8. Stockdale, R., Standing, C.: A classification model to support SME e-commerce adoption initiatives. Journal of Small Business and Enterprise Development 13, 381-394 (2006)

9. Dilworth, A.J., Kochhar, A.K.: Creation of an e-business requirements specification model. Journal of Manufacturing Technology Management 18, 659-677 (2007) 